\title{
Distinguishing between anthropogenic and climatic impacts on lake size: a modeling approach using data from Ebinur Lake in arid northwest China
}

\author{
Long MA, ${ }^{1}$ Jinglu WU,,$^{2 *}$ Wen LIU, ${ }^{2}$ Jilili ABUDUWAILI ${ }^{1}$ \\ ${ }^{1}$ State Key Laboratory of Desert and Oasis Ecology, Xinjiang Institute of Ecology and Geography, Chinese Academy of Sciences, \\ Urumqi 830011, China; ${ }^{2}$ State Key Laboratory of Lake Science and Environment, Nanjing Institute of Geography and Limnology, \\ Chinese Academy of Sciences, Nanjing 210008, China \\ *Corresponding author: w.jinglu@niglas.ac.cn
}

\begin{abstract}
Evaluation of anthropogenic and climatic impacts on lake size variation is important for maintaining ecosystem integrity and sustaining societal development. We assumed that climate and human activity are the only drivers of lake-size variation and are independent of each other. We then evaluated anthropogenic and climatic effects on hydrological processes, using a multivariate linear model. Macro-economic data were used to describe the anthropogenic impact on lake surface area in our approach. Ebinur Lake is a shallow, closed, saline lake in arid northwest China; it has shrunk at a rapid rate over the past half century. Using our new method, we explored temporal trends of anthropogenic and climatic impacts on the lake over the past 50 years. Assessment indices indicate that the model represents observed data quite well. Compared with the reference period of 1955-1960, impacts of climate change across the catchment were generally positive with respect to lake area, except for the period from 1961 to 1970. Human activity was responsible for a reduction in lake surface area of $286.8 \mathrm{~km}^{2}$ over the last 50 years. Our approach, which uses economic variables to describe the anthropogenic impact on lake surface area, enables us to explain the lake responses to climate change and human activities quantitatively.
\end{abstract}

Key words: Quantitative analysis, anthropogenic and climatic effects, Ebinur Lake, China.

Received: August 2013. Accepted: January 2014.

\section{INTRODUCTION}

Surface air temperature in central Asia has undergone a striking warming trend (Lioubimtseva, 2004; Chen et al., 2009) and aridity may also have increased across the region during the past century. These effects are pronounced in the western region (Lioubimtseva and Henebry, 2009). The past century also marked the change from a climate system dominated by natural influences, to one dominated by anthropogenic activities (Brönnimann et al., 2007). Demand for water also increased during that time, with greater regional industry and agriculture in central Asia (O'Hara, 2000; Saiko and Zonn, 2000; Qi et al., 2005).

Lakes play an essential role in the regional water cycle and reflect watershed water balance in arid regions (Lamb et al., 1999; Williams, 1999; Ma et al., 2011a). In arid central Asia, rapid shrinking of the Aral Sea, Lop Nur, Manas Lake, and Ebinur Lake reflects regional environmental effects and threatens human livelihoods (Ma et al., 2011a). For example, the surface area of Ebinur Lake was reduced from $1107 \mathrm{~km}^{2}$ in 1955 to $428 \mathrm{~km}^{2}$ in 2010 . The exposed land surface became a vast bare solonchak with large salt deposits, predominantly sodium sulfates. The northwestern winds blowing from the Dzungarian Gate move the salt-dust hundreds of kilometers (Abuduwaili et al., 2008).
Increasing environmental and ecological awareness led us to explore reliable methods to evaluate the impact of anthropogenic factors and climatic variability on the evolution of the lake (Gell et al., 2007; Dearing et al., 2006). In previous work, Wu and Lin (2004) simply compared lake area with precipitation and agricultural irrigation water demand at decadal resolution. Zhou et al. (2010) analyzed the correlation between lake area and meteorological variables, and concluded that precipitation was one of the most important factors. In this paper, macro-economic data were used to describe the anthropogenic impact on lake size, and then, the anthropogenic and climatic effects on the size of Ebinur Lake were quantitatively evaluated.

\section{Regional setting}

Ebinur Lake is a shallow, closed lake in arid northwest China (Fig. 1). The lake has a drainage area of 50,321 $\mathrm{km}^{2}$, including $24,317 \mathrm{~km}^{2}$ of mountainous terrain. Ala Mountain borders the lake to the north and northwest, Boertala Valley is to the west, the Jing River pluvial fan is to the south, and sand dunes around the Kuitun River are to the east. Mean annual precipitation around the lake is about $95 \mathrm{~mm}$, whereas annual evaporation is $1315 \mathrm{~mm}$ (Wu et al., 2009). The lake has a maximum water depth 
of $3.5 \mathrm{~m}$ and an average depth of $1.2 \mathrm{~m}$. The lake water has 85-124 $\mathrm{g} \mathrm{L}^{-1}$ of total dissolved solids. Ebinur Lake receives surface water inputs from the Bo and Jing Rivers. The Ala Mountain pass, northwest of the lake, is a wellknown wind corridor, with wind speeds exceeding $20 \mathrm{~m}$ $\mathrm{s}^{-1}$ on 164 days of the year and maximum wind speeds of up to $55 \mathrm{~m} \mathrm{~s}^{-1}$ (Wu et al., 2009; Ma et al., 2011b).

\section{METHODS}

\section{Data collection}

Ebinur Lake surface-area data are from previous research (Ma et al., 2011b). We interpolated data on lake surface area to annual resolution using linear interpolation, and used the annual values in the modeling approach. Climate data recorded at the Jinghe meteorological station (82 $54^{\prime} \mathrm{N}, 4^{\circ} 37^{\prime} \mathrm{E}, 321.2 \mathrm{~m}$ ) were provided by China's meteorological data-sharing service. Measured meteorological variables, and the resolution with which they were reported, included mean annual precipitation $(0.1 \mathrm{~mm})$, barometric pressure $(0.1 \mathrm{hPa})$, wind speed $\left(0.1 \mathrm{~m} \mathrm{~s}^{-1}\right)$, annual surface air temperature $\left(0.1^{\circ} \mathrm{C}\right)$, water vapor pressure
$(0.1 \mathrm{hPa})$, relative humidity $(\%)$, percent sunshine $(\%)$ and sunshine duration (0.1 hour) (Supplementary Tab. 1).

Economic data, used as a proxy for anthropogenic impact, are from the Xinjiang economic statistics yearbooks. Economic variables included population $\left(10^{4}\right.$ persons), gross domestic product (GDP) $\left[10^{4} \mathrm{CNY}, 1 \mathrm{CNY}\right.$ (Chinese Yuan $)=0.16$ USD (US Dollar)], the primary industry $\left(10^{4} \mathrm{CNY}\right)$, secondary industry $\left(10^{4} \mathrm{CNY}\right)$ and tertiary industry $\left(10^{4} \mathrm{CNY}\right)$, total investment in fixed assets $\left(10^{4}\right.$ $\mathrm{CNY})$, total sown area of farm crops $\left(10^{3} \mathrm{ha}\right)$, total sown area of food crops $\left(10^{3} \mathrm{ha}\right)$, food production $\left(10^{3} \mathrm{~kg}\right)$, cotton production $\left(10^{3} \mathrm{~kg}\right)$ and oil crops production $\left(10^{3} \mathrm{~kg}\right)$ (Supplementary Tab. 2).

\section{Quantitative analysis: a multivariate linear model}

Multivariate regression was used to distinguish between climatic and anthropogenic impacts on observed lake surface area fluctuation in the past 50 years (eq. 1). The standard linear regression model assumes the value of $\mathrm{Y}$ has a linear form with the set of predictor variables $\left(\mathrm{X}_{1}, \mathrm{X}_{2}, \mathrm{X}_{3} \ldots, \mathrm{X}_{\mathrm{p}}\right)$, as follows:

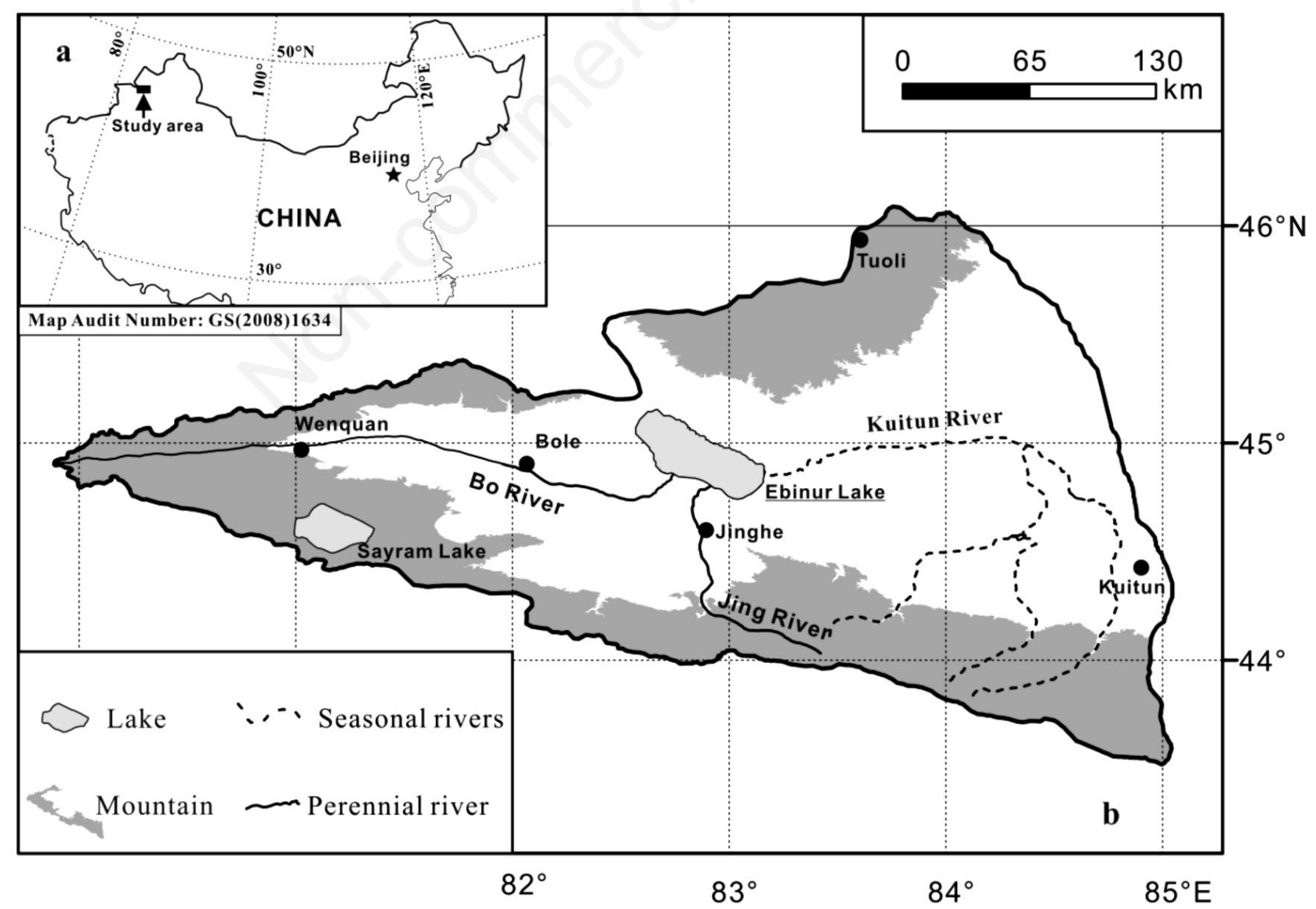

Fig. 1. Location of Ebinur Lake (a) and its watershed in northwest China (b). 
$\mathrm{Y}=\mathrm{f}\left(\mathrm{X}_{1}, \mathrm{X}_{2}, \mathrm{X}_{3} \ldots, \mathrm{X}_{\mathrm{p}}\right)=$

$\beta_{0}+\beta_{1} X_{1}+X_{2} \beta_{2}+X_{3} \beta_{3}+\ldots+X_{p} \beta_{p}$

The surface area of Ebinur Lake was the dependent variable Y (Fig. 2). For a closed lake, hydrologic inputs included direct precipitation, stream and groundwater inflows. Outputs were evaporation and transpiration. In the Ebinur Lake catchment, there were insufficient hydrological data to complete a water balance analysis; consequently, hydrology was accounted for indirectly using climate and economic data. Industrial demand and agricultural irrigation in the catchment increase water consumption and reduce runoff, which directly affects lake surface area. We captured this economic development in economic data published by the government.

We used principal component analysis (PCA) (Pardo et al., 1990) of the climatic and economic data to find the latent variables $\left(\mathrm{X}_{1}, \mathrm{X}_{2}, \mathrm{X}_{3} \ldots, \mathrm{X}_{\mathrm{p}}\right)$ to explain the original variance and to simultaneously reduce the dimensionality of the dataset. We completed the PCA for climatic and economic variables separately to reduce the number of variables and extract latent variables for multivariate regression. The extracted climatic and economic variables, however, have some degree of correlation. We used partial least squares (PLS) modeling to eliminate potential collinearity among the independent, latent variables $\left(\mathrm{X}_{1}, \mathrm{X}_{2}, \mathrm{X}_{3} \ldots, \mathrm{X}_{\mathrm{p}}\right)$. PLS was first introduced by H. Wold (1975) under the name NIPALS (nonlinear iterative partial least squares), which focuses on maximizing the variance of the dependent variables explained by the independent ones, instead of reproducing the empirical covariance matrix (Haenlein and Kaplan, 2004). A PLS model consists of a structural part, which reflects the relationships between the latent variables, and a measurement component, which shows how the latent variables and their indicators are related; but it also has a third component, weight relations, which

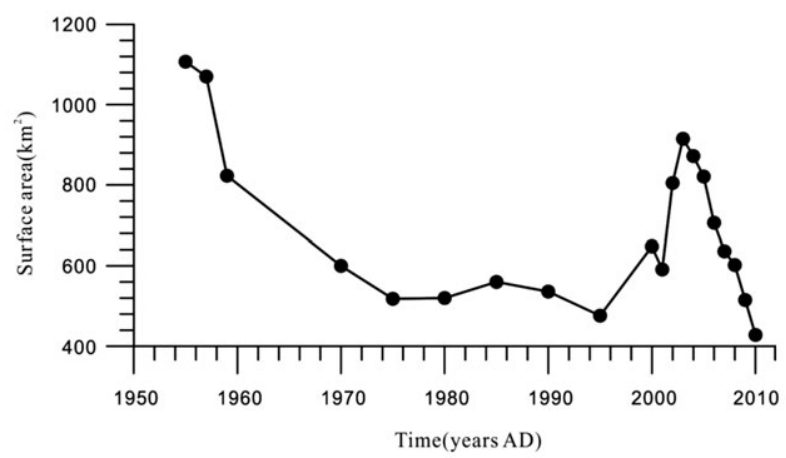

Fig. 2. Change in surface area of Ebinur Lake over the past 50 years. are used to estimate case values for the latent variables (Chin and Newsted, 1999). Haenlein and Kaplan (2004) provided a comprehensible introduction to this technique. Partial least squares regression analysis is appropriate when the matrix of predictors has more variables, and when there is multi-collinearity among $\mathrm{X}$ values. By contrast, standard regression will fail in these cases. PLS regression was achieved using the Unscrambler software package (CAMO ASA, 1997). We completed PCA analysis and linear interpolation in R STATS packages (R Core Team, 2012).

\section{Assessment indices for the multivariate linear model}

We used the Nash-Sutcliffe efficiency (NSE) ratio (Nash and Sutcliffe, 1970) of the root mean square error to the standard deviation of measured data (RSR), and percentage bias (PBIAS) to evaluate the model (Moriasi et al., 2007). They are as follows:

$$
\begin{aligned}
& \text { NSE }=1-\frac{\sum_{i=1}^{n}\left(X_{i}-\widehat{X}_{i}\right)^{2}}{\sum_{i=1}^{n}\left(X_{i}-\bar{X}\right)^{2}} \\
& \text { RSR }=\frac{\sqrt{\sum_{i=1}^{n}\left(X_{i}-\widehat{X}_{i}\right)^{2}}}{\sqrt{\sum_{i=1}^{n}\left(X_{i}-\bar{X}\right)^{2}}} \\
& \text { PBIAS }=\frac{\sum_{i=1}^{n}\left(X_{i}-\widehat{X}_{i}\right) \times 100}{\sum_{i=1}^{n} X_{i}}
\end{aligned}
$$

where $X_{i}, \hat{X}_{i}, \bar{X}$ and $\mathrm{n}$ are, respectively, the observed value, the predicted value, the mean value of the observed data, and the number of observations. The theoretical range of NSE is from $-\infty$ to 1 , with $\mathrm{NSE}=1$ being the optimal value. Values between 0.0 and 1.0 are generally viewed as acceptable levels of performance, whereas values $<0.0$ indicate that the mean observed value is a better predictor than the simulated value, which indicates unacceptable performance. The RSR varies from the optimal value of 0 , which indicates zero root mean square error (RMSE), or residual variation, and therefore perfect model simulation, to a large positive value. Lower RSR implies lower RMSE and better model simulation performance (Moriasi et al., 2007). The PBIAS measures the average tendency of the simulated data to be larger or smaller than their observed counterparts. The optimal value of PBIAS is 0.0 , with low values indicating accurate model simulation (Gupta et al., 1999). 


\section{RESULTS}

\section{Variation of lake surface area over the past 50 years}

The evolution of the lake was divided into four periods (Fig. 2). During the first period, which ended in 1975, the lake shrank sharply. In the second period (1975-1995), lake area was relatively stable and was $476 \mathrm{~km}^{2}$ in 1995 . The lake had an historically large area of $915 \mathrm{~km}^{2}$ in 2003 , and subsequently decreased to $428 \mathrm{~km}^{2}$ in 2010 .

\section{Latent variables extracted from the climate and economic data}

Four climate factors accounted for $93 \%$ of the total variance in the PCA (Tab. 1). The remaining factors did not contribute significantly to information in the data matrix. The first factor (PC1 climate), spanning $49 \%$ of the variance, was related well to precipitation, wind speed, water vapor pressure, relative humidity, percent sunshine and sunshine duration. Temperature and station pressure were significantly correlated with PC2_climate. PC3_climate and PC4 climate accounted for $13 \%$ and $9 \%$ of total variance, respectively. The four principal components, as independent variables $\left(\mathrm{X}_{1}, \mathrm{X}_{2}, \mathrm{X}_{3}\right.$ and $\left.\mathrm{X}_{4}\right)$ in the multivariable linear model, represented climate change over the past 50 years (Supplementary Tab. 3).

Three social and economic factors accounted for $95 \%$ of total variance and the remaining factors were not significant (Tab. 2). PC2_human and PC3_human accounted for $18 \%$ and $7 \%$ of total variance, respectively. $\mathrm{PC} 1$ human accounted for $70 \%$ of total variance, and was positively correlated with population, gross domestic product, primary industry, secondary industry, tertiary industry, total invest- ment in fixed assets and total sown area of farm crops. The three principal components, as independent variables $\left(\mathrm{X}_{5}\right.$, $\mathrm{X}_{6}$ and $\mathrm{X}_{7}$ ) in the multivariable linear model, represented human activities (Supplementary Tab. 3).

\section{Assessment of the multivariate linear model}

In our model, parameters $\mathrm{X}_{1}, \mathrm{X}_{2}, \ldots, \mathrm{X}_{7}$ extracted from the PCA, were assigned to the independent variables, and lake area was assigned to the dependent variable (Y) (Supplementary Tab. 3). The best match between the observed lake-surface area and the model predicted value is shown in Fig. 3. The regression coefficients $\left(\beta_{1}, \beta_{2}, \beta_{3} \ldots, \beta_{7}\right)$ were $21.83,-35.64,-30.11,-4.458,-47.57,-132.86$ and -69.02 , respectively. We use equation (5) to calculate the standard error of the estimate (SE).

$S E=\sqrt{\frac{\sum\left(Y-Y^{\prime}\right)^{2}}{N}}$

here $\mathrm{Y}$ is an observed score, $\mathrm{Y}^{\prime}$ is a predicted score, and $\mathrm{N}$ is the number of pairs of scores. The standard error of the estimate (SE) was 78.42. There was a good linear correlation between the predicted values and the original lake area data $(\mathrm{r}=0.87, \mathrm{P}<0.01)$. All correlation coefficients were significant at the $\mathrm{P}<0.01$ level; the predicted surface area data were significantly correlated with observed data.

Model assessment indices were NSE $=0.76, \mathrm{RSR}=0.49$, and PBIAS $=0$. Based on general performance ratings for recommended statistics (Tab. 3) (Moriasi et al., 2007), our model was very good and the reconstructed annual surface area of Ebinur Lake was described well by the model.

Tab. 1. Total variance explained and component matrixes (four factors selected) for climate data.

\begin{tabular}{|c|c|c|c|c|}
\hline \multirow[t]{2}{*}{ Vector } & \multicolumn{4}{|c|}{ Initial Eigenvalues } \\
\hline & \multicolumn{2}{|c|}{ Eigenvalue } & Total variance $(\%)$ & Cumulative (\%) \\
\hline 1 & \multicolumn{2}{|c|}{3.91} & 48.90 & 48.90 \\
\hline 2 & \multicolumn{2}{|c|}{1.76} & & 70.88 \\
\hline 3 & \multicolumn{2}{|c|}{1.08} & & 84.33 \\
\hline 4 & \multicolumn{2}{|c|}{0.70} & & 93.04 \\
\hline 5 & \multicolumn{2}{|c|}{0.28} & & 96.49 \\
\hline$\cdots$ & \multicolumn{2}{|c|}{$\cdots$} & & $\ldots$ \\
\hline \multicolumn{5}{|l|}{ Component matrixes } \\
\hline & PC1_climate $\left(\mathrm{X}_{1}\right)$ & PC2_climate $\left(\mathrm{X}_{2}\right)$ & PC3_climate $\left(\mathrm{X}_{3}\right)$ & PC4_climate $\left(\mathrm{X}_{4}\right)$ \\
\hline Precipitation & 0.78 & -0.04 & 0.39 & -0.34 \\
\hline Barometric pressure & 0.49 & 0.73 & -0.13 & 0.27 \\
\hline Wind speed & -0.62 & 0.34 & 0.33 & -0.58 \\
\hline Temperature & 0.02 & -0.95 & 0.09 & 0.03 \\
\hline Water vapor pressure & 0.76 & -0.27 & 0.52 & 0.21 \\
\hline Relative humidity & 0.81 & 0.34 & 0.38 & 0.07 \\
\hline Percent sunshine & -0.86 & 0.10 & 0.43 & 0.26 \\
\hline Sunshine duration & -0.85 & 0.10 & 0.44 & 0.25 \\
\hline
\end{tabular}

Extraction method: Principal Component Analysis. 


\section{Contribution of climate change and human activities to change in the surface area of Ebinur Lake}

We define a comprehensive climatic factor as $\Phi_{\text {climate }}=\beta_{1} X_{1}+X_{2} \beta_{2}+X_{3} \beta_{3}+X_{4} \beta_{4}$, and a comprehensive anthropogenic factor as $\Phi_{\text {human }} \beta_{5} X_{5}+X_{6} \beta_{6}+X_{7} \beta_{7}$. A change in the surface area of Ebinur Lake can be calculated as follows: $\Delta \mathrm{E}_{\text {predicted }}=\mathrm{E} 2_{\text {_average }}-\mathrm{E} 1_{\text {_average}}$, where $\Delta \mathrm{E}_{\text {predicted }}$ is the predicted surface area change between two different stages, $\mathrm{E} 1_{\text {average }}$ is the average lake surface area during the refer- ence stage, and $\mathrm{E} 2$ average is the average annual surface area during the following stage. The change in lake area was also estimated as follows: $\Delta \mathrm{E}_{\text {predicted }}=\Delta \bar{\Phi}_{\text {climate }}+\Delta \bar{\Phi}_{\text {human, }}$, the impact of climatic change on lake surface area $\Delta \bar{\Phi}_{\text {climate }}=\bar{\Phi}_{\text {climate-2 }}-\bar{\Phi}_{\text {climate-1 }}$, where $\bar{\Phi}_{\text {climate-1 }}$ is the average value of $\Phi_{\text {climate }}$ during the reference stage, and $\bar{\Phi}_{\text {climate-2 }}$ is the average value of $\Phi_{\text {climate }}$ during the following stage. The impact of human activities on lake surface area $\Delta \bar{\Phi}_{\text {human }}=\bar{\Phi}_{\text {human-2 }}-\bar{\Phi}_{\text {human-1 }}$, where $\bar{\Phi}_{\text {human-1 }}$ is the average

Tab. 2. Total variance explained and component matrixes (three factors selected) for human activity.

\begin{tabular}{|c|c|c|c|}
\hline \multirow[t]{2}{*}{ Vector } & \multicolumn{3}{|c|}{ Initial Eigenvalues } \\
\hline & Eigenvalue & Total variance $(\%)$ & Cumulative (\%) \\
\hline 1 & 7.68 & 69.77 & 69.77 \\
\hline 2 & 1.98 & 18.02 & 87.79 \\
\hline 3 & 0.76 & 6.92 & 94.72 \\
\hline 4 & 0.37 & 3.35 & 98.06 \\
\hline$\cdots$ & $\cdots$ & $\cdots$ & $\cdots$ \\
\hline \multicolumn{4}{|l|}{ Component matrixes } \\
\hline & $\mathrm{PC1}$ _human $\left(\mathrm{X}_{5}\right)$ & $\mathrm{PC} 2$ human $\left(\mathrm{X}_{6}\right)$ & PC3_human $\left(\mathrm{X}_{7}\right)$ \\
\hline Population & 0.76 & 0.60 & -0.14 \\
\hline Gross domestic product & 0.99 & -0.05 & 0.11 \\
\hline Primary industry & 0.97 & -0.02 & 0.15 \\
\hline Secondary industry & 0.97 & -0.01 & 0.20 \\
\hline Tertiary industry & 0.98 & -0.10 & 0.01 \\
\hline Total investment in fixed assets & 0.97 & -0.14 & 0.18 \\
\hline Total sown area of farm crops & 0.93 & 0.29 & 0.13 \\
\hline Food crops & -0.63 & 0.06 & 0.75 \\
\hline Food production & -0.17 & 0.91 & -0.11 \\
\hline Cotton production & 0.98 & 0.02 & -0.13 \\
\hline Oil crops production & -0.30 & 0.82 & 0.16 \\
\hline
\end{tabular}

Extraction method: Principal Component Analysis.
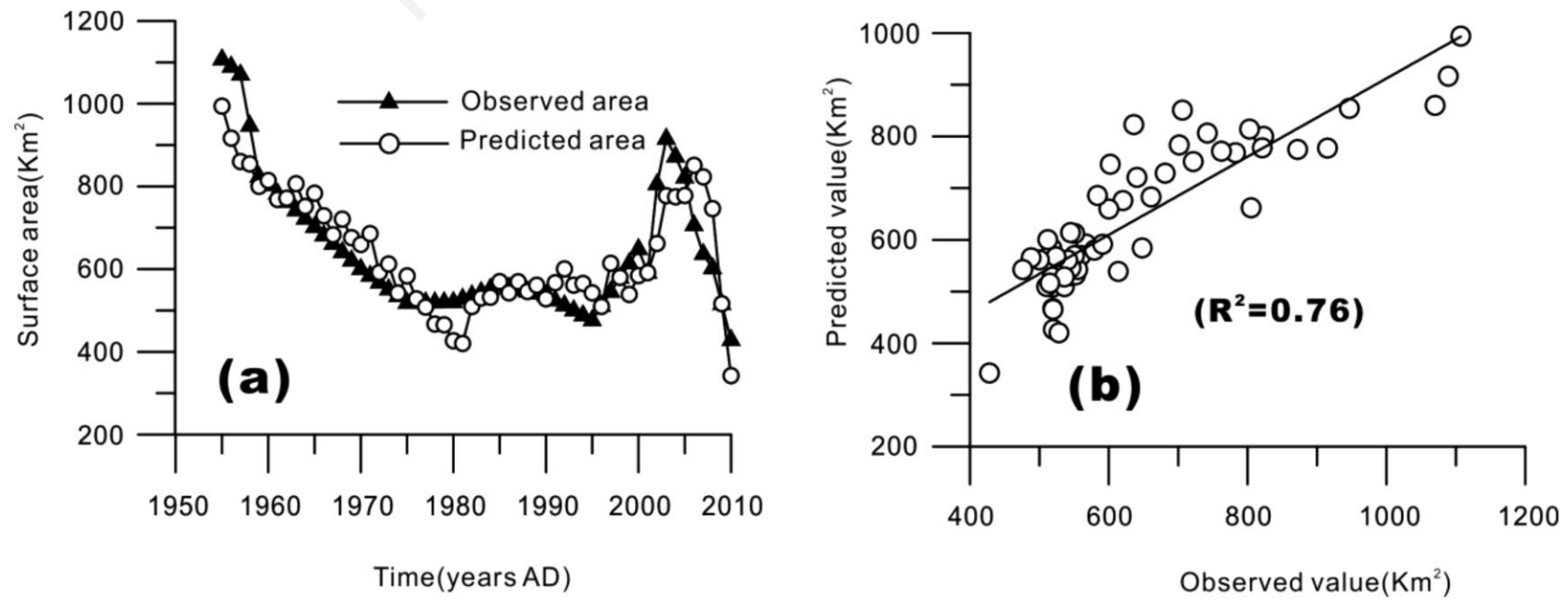

Fig. 3. Comparison of the surface area of Ebinur Lake, predicted by our model, with the observed surface area. 
value of $\Phi_{\text {human }}$ during the reference stage, and $\bar{\Phi}_{\text {human-2 }}$ is the average value of $\Phi_{\text {human }}$ during the following stage. When compared to the reference stage of 1955-1960, the impacts of climate change across the catchment were generally positive for Ebinur Lake except during the 19611970 stage (Tab. 4). Based on our model, climate change increased annual lake area by $50.6 \mathrm{~km}^{2}, 22.8 \mathrm{~km}^{2}, 12.6$ $\mathrm{km}^{2}$ and $38.2 \mathrm{~km}^{2}$ in the $1970 \mathrm{~s}, 1980 \mathrm{~s}, 1990 \mathrm{~s}$ and $2000 \mathrm{~s}$, respectively. The impacts of human activities increased during the 1960s, 1970s and 1980s (Tab. 4, $\Delta \bar{\Phi}_{\text {human }}$ ). Compared with previous stages, anthropogenic impacts on lake variation decreased from 1991 to 2010 (a positive value for $\Delta \bar{\Phi}_{\text {human }}$ in 1990s and 2000s).

\section{DISCUSSION}

Regression coefficients for the climate and economic variables were $\left(\beta_{1=} 21.83, \beta_{2}=-35.64, \beta_{3}=-30.12, \beta_{4}=-4.46\right.$, $\beta_{5}=-47.57, \beta_{6}=-132.86$, and $\left.\beta_{7}=-69.02\right)$. Among the PCAextracted economic variables, $\mathrm{X}_{6}$ had the greatest weight coefficient and reflected the change in food production. Water demand for agricultural irrigation was the main factor for water consumption in the Ebinur Lake watershed.

The surface area of Ebinur Lake shrank from 2330 $\mathrm{km}^{2}$ ca. $4.5 \mathrm{ka}$ BP to $1107 \mathrm{~km}^{2}$ in 1955 , whereas the lake shrank from $1107 \mathrm{~km}^{2}$ in 1955 to $428 \mathrm{~km}^{2}$ in 2010 (Ma et al. 2011a). Sayram Lake is another lake in the Ebinur Lake catchment. There are no residential villages or agricultural development around Sayram Lake. The surface area of Sayram Lake was relatively stable from 1960 $\left(443.9 \mathrm{~km}^{2}\right)$ to $1987\left(448.3 \mathrm{~km}^{2}\right)$. In 1988 , the lake area increased to $459 \mathrm{~km}^{2}$ and has remained high since then
(Wu and Ma, 2011). Human activity was responsible for Ebinur Lake shrinking by $286.8 \mathrm{~km}^{2}$ over the past half century. Assuming only climate impacts on lake variation (i.e., no human activities in the watershed), the lake would have expanded from $873.3 \mathrm{~km}^{2}$ in the 1960 s to $973.2 \mathrm{~km}^{2}$ in the 2000s. On 1 October 1955, the Xinjiang Uygur Autonomous Region was established, opening new possibilities for development in Xinjiang. During the past half century, Xinjiang's economy has advanced rapidly, as has its social undertakings. Although climatic conditions alone would have led to a $99.8 \mathrm{~km}^{2}$ increase in lake surface area, intensive human activities in the catchment over the past 50 years led to the shrinkage of Ebinur Lake.

Although our model works well in terms of assessment statistics, the model could be improved. In some years, not all data were measured, and we estimated these missing values by linear interpolation. Of the 56 data points for lake surface area in the model, only 20 were measured directly. Consequently, the climate and economic variables cannot exactly reflect lake surface area, and this effect partly explains the difference between the observed and predicted values for lake surface area.

For Ebinur Lake, precipitation, stream input, groundwater inflow, evaporation and transpiration were direct factors influencing lake surface area. These factors were indirectly influenced by interactions between climate and human activities. Moreover, the internal mechanisms that determine how climatic and economic variables influenced lake size were complex and can only be expressed by linear mathematical formulas. These all affect our model for estimating lake surface area.

Tab. 3. General performance ratings for recommended statistics from Moriasi et al. (2007).

\begin{tabular}{lccc}
\hline Performance rating & RSR & NSE & PBIAS (\%) \\
\hline Very good & $0.00 \leq \mathrm{RSR} \leq 0.50$ & $0.75<\mathrm{NSE} \leq 1.00$ & PBIAS $< \pm 10$ \\
Good & $0.50<\mathrm{RSR} \leq 0.60$ & $0.65<\mathrm{NSE} \leq 0.75$ & $\pm 10 \leq$ PBIAS $< \pm 15$ \\
Satisfactory & $0.60<\mathrm{RSR} \leq 0.70$ & $0.50<\mathrm{NSE} \leq 0.65$ & $\pm 15 \leq$ PBIAS $< \pm 25$ \\
Unsatisfactory & $\mathrm{RSR}>0.70$ & $\mathrm{NSE} \leq 0.50$ & PBIAS $\geq \pm 25$ \\
\hline
\end{tabular}

RSR, root mean square; NSE, Nash-Sutcliffe efficiency; PBIAS, percentage bias.

Tab. 4. Contribution of climate change and human activities to change of Ebinur Lake surface area.

\begin{tabular}{lccccc}
\hline Stages & Periods (AD) & $\bar{E}_{i}\left(\mathrm{~km}^{2}\right)$ & $\Delta \bar{E}^{\circ}\left(\mathrm{km}^{2}\right)$ & $\Delta \bar{\Phi}_{\text {climate }}\left(\mathrm{km}^{2}\right)$ & - \\
\hline 1 & $1955-1960$ & 873.3 & - & -24.3 & -114.0 \\
2 & $1961-1970$ & 735.0 & -138.3 & 50.5 & -244.4 \\
3 & $1971-1980$ & 541.2 & -193.8 & 22.8 & -33.1 \\
4 & $1981-1990$ & 530.9 & -10.3 & 12.6 & 22.9 \\
5 & $1991-2000$ & 566.4 & 35.5 & 38.2 & 81.7 \\
6 & $2001-2010$ & 686.3 & 119.9 & 99.8 & -286.8 \\
Sum & - & - & -187.0 & $\left.\mathrm{\Phi m}^{2}\right)$
\end{tabular}

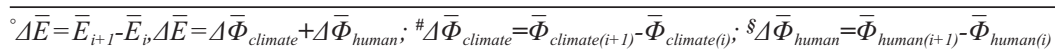




\section{CONCLUSIONS}

Economic variables were used as proxies for anthropogenic impact on Ebinur Lake size. Seven independent variables were extracted from a larger set of variables using Principal Component Analysis (PCA), which accounted for $93 \%$ and $95 \%$ of climate and economic development variation, respectively.

A multivariate regression with the principal components as independent variables was conducted and was used to distinguish between climate and anthropogenic impacts on the lake surface area. There was a good linear correlation between the predicted and observed data $(\mathrm{r}=0.87, \mathrm{P}<0.01)$. We conclude that human activity was responsible for the lake surface area reduction of 286.8 $\mathrm{km}^{2}$ over the past half century. In the absence of human activities in the watershed, climate conditions would have led to a $99.8 \mathrm{~km}^{2}$ increase in lake surface area.

\section{ACKNOWLEDGMENTS}

We thank two anonymous reviewers, the journal editor, and Mark Brenner for their helpful comments and suggestions. We also thank the National Meteorological Information Center, China Meteorological Administration for providing us with the climate data. This research was supported by the International Science \& Technology Cooperation Program of China (2010DFA92720), West Doctor Project of West Light Foundation (XBBS201106), National Basic Research Program of China (2012CB956102), National Natural Science Foundation of China (41101190, U1138301), and China Postdoctoral Science Foundation (20110491752). The authors also gratefully acknowledge the support of Youth Innovation Promotion Association, Chinese Academy of Sciences and K.C. Wong Education Foundation, Hong Kong.

\section{REFERENCES}

Abuduwaili J, Gabchenko M, Xu J, 2008. Eolian transport of salts-a case study in the area of Lake Ebinur (Xinjiang, Northwest China). J. Arid Environ. 72:1843-1852.

Brönnimann S, Ewen T, Luterbacher J, Diaz H, Stolarski R, Neu U, 2007. A focus on climate during the past 100 years, p. 125. In: S. Brönnimann, J. Luterbacher, T. Ewen, H. Diaz, R.S. Stolarski and U. Neu (eds.), Climate variability and extremes during the past 100 years. Springer.

CAMO ASA, 1997. Unscrambler Users Guide, ver. 6.11a. Programme Package for Multivariate Calibration. Trondheim, Norway.

Chen F, Wang J, Jin L, Zhang Q, Li J, Chen J, 2009. Rapid warming in mid-latitude central Asia for the past 100 years. Front. Earth Sci. China 3:42-50.

Chin WW, Newsted PR, 1999. Structural equation modelling analysis with small samples using partial least squares, p.3 07-341. In: R.H. Hoyle (ed.), Statistical strategies for small sample research. Sage Publ., Thousand Oaks, CA.
Dearing J, Battarbee R, Dikau R, Larocque I, Oldfield F, 2006. Human-environment interactions: learning from the past. Reg. Environ. Change 6:1-16.

Gell P, Fritz S, Battarbee R, Tibby J, 2007. LIMPACS-Human and Climate Interactions with Lake Ecosystems: setting research priorities in the study of the impact of salinisation and climate change on lakes, 2005-2010. Hydrobiologia 591:99-101.

Gupta HV, Sorooshian S, Yapo PO, 1999. Status of automatic calibration for hydrologic models: Comparison with multilevel expert calibration. J. Hydrol. Eng. 4:135-143.

Haenlein M, Kaplan AM, 2004. A beginner's guide to partial least squares analysis. Understand. Stat. 3:283-297.

Lamb H, Roberts N, Leng M, Barker P, Benkaddour A, van der Kaars S, 1999. Lake evolution in a semi-arid montane environment: response to catchment change and hydroclimatic variation. J. Paleolimnol. 21:325-343.

Lioubimtseva E, 2004. Climate change in arid environments: revisiting the past to understand the future. Prog. Phys. Geog. 28:502-530

Lioubimtseva E, Henebry GM, 2009. Climate and environmental change in arid Central Asia: Impacts, vulnerability, and adaptations. J. Arid Environ. 73:963-977.

Ma L, Wu J, Abuduwaili J, 2011a. The climatic and hydrological changes and environmental responses recorded in lake sediments of Xinjiang, China. J. Arid Land 3:1-8.

Ma L, Wu J, Yu H, Zeng H, Abuduwaili J, 2011b. The medieval warm period and the little Ice age from a sediment record of Lake Ebinur, Northwest China. Boreas 40:518-524.

Moriasi D, Arnold J, Van Liew M, Bingner R, Harmel R, Veith T, 2007. Model evaluation guidelines for systematic quantification of accuracy in watershed simulations. T. ASABE 50:885-900.

Nash J, Sutcliffe J, 1970. River flow forecasting through conceptual models part I-A discussion of principles. J. Hydrol. 10:282-290.

O'Hara SL, 2000. Lessons from the past: water management in Central Asia. Water Policy 2:365-384.

Pardo R, Barrado E, Perez L, Vega M, 1990. Determination and speciation of heavy metals in sediments of the Pisuerga river. Water Res. 24:373-379.

Qi F, Liu W, Si J, Su Y, Zhang Y, Cang Z, Xi H, 2005. Environmental effects of water resource development and use in the Tarim River basin of northwestern China. Environ. Geol. 48:202-210.

R Core Team, 2013. R: A language and environment for statistical computing. R Foundation for Statistical Computing, Vienna, Austria. Available from: http://www.Rproject.org/

Saiko TA, Zonn IS, 2000. Irrigation expansion and dynamics of desertification in the Circum-Aral region of Central Asia. Appl. Geogr. 20:349-367.

Williams WD, 1999. Salinisation: A major threat to water resources in the arid and semi-arid regions of the world. Lakes Reserv. Res. Manage. 4:85-91.

Wold H, 1975. Path models with latent variables: The NIPALS approach, p. 307-357. In: H.M. Blalock, A. Aganbegian, F.M. Borodkin, R. Boudon and V. Capecchi (eds.), Quantitative sociology: international perspectives on mathematical and statistical modeling. Academic Press, NewYork. 
Wu J, Lin L, 2004. [Characteristics and reasons of fluctuation of lake surface of the Aibi Lake, Xinjiang autonomous region].[Article in Chinese with English Abstract]. Mar. Geol. Quat. Geol. 24:57-60.

Wu J, Ma L, 2011. [Lake evolution and climatic and hydrological changes in arid zone of Xinjiang].[Article in Chinese with English Abstract]. Mar. Geol. Quat. Geol. 31:135-143.
Wu J, Yu Z, Zeng HA, Wang N, 2009. Possible solar forcing of 400 -year wet-dry climate cycles in northwestern China. Climatic Change 96:473-482.

Zhou C, He L, Yang N, 2010. [Variations in the Ebinur Lake area caused by human activities and climatic changes].[Article in Chinese with English Abstract]. Mar. Geol. Quat. Geol. 30: 121-126. 